\title{
Evaluation of the Tuberculosis Prevention Program in the Discovery of Tuberculosis Cases in Nosara Public Health Center Palu City
}

\author{
Muhammad Rizki Ashari ${ }^{1 *}$ (D), Irma Apriani ${ }^{1}$, Firmansyah Firmansyah ${ }^{2}$, Fitrianty Sutady Lanyumba ${ }^{1}$ \\ ${ }^{1}$ Department of Health Administration and Policy, Faculty of Public Health, Tadulako University, Palu, Indonesia; ${ }^{2}$ Department \\ of Health Promotion, Faculty of Public Health, Tadulako University, Palu, Indonesia
}

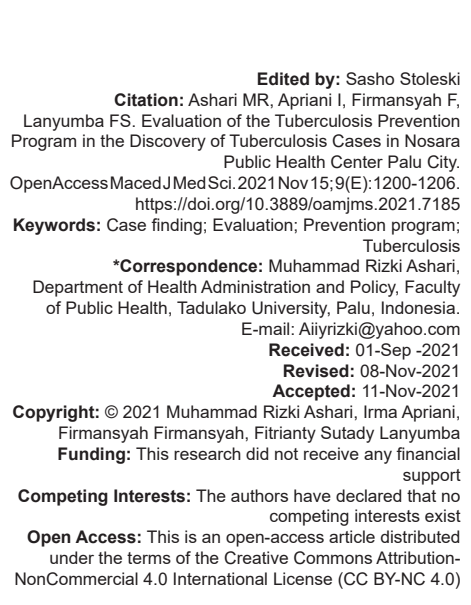

\section{Introduction}

Tuberculosis (TB) is an infectious disease caused by Mycobacterium tuberculosis. The source of transmission is positive Bakteri Tahan Asam (Acid Resistant Basil) TB patients. Pulmonary TB patients with smear positive present the possibility of a greater risk of transmission than patients with smear negative pulmonary TB [1].

Globally, an estimated 10.0 million people fell ill with TB in 2018 and among them men (aged $\geq 15$ years), which accounted for $57 \%$ of all TB cases in $2018,32 \%$ of women and children (aged $<15$ years) by $11 \%$. Geographically, most of the TB cases in 2018 were in Southeast Asia (44\%), Africa (24\%) and the Western Pacific (18\%), with a smaller percentage in the East Mediterranean (8\%), America (3\%), and Europe (3\%). Eight countries account for two-thirds of the global total: India found 2,155,894 (27\%) TB cases, China found 801,532 TB cases, Indonesia $570,289(8 \%)$ TB cases, the Philippines 382,543 TB cases $(6 \%)$, Pakistan found 369,548 TB cases $(6 \%)$, Nigeria found 105,533 TB cases (4\%), Bangladesh
268,596 TB cases (4\%), and South Africa 235,652 TB cases (3\%) [2].

TB cases in Indonesia are in the third rank with the highest number of TB cases in the world. In 2016 in Indonesia there were 360,565 TB cases, then increased in 2017, it was found the number of TB cases was 425,089 cases, in 2018 there were the number of TB cases with all types, namely 511,873 cases. West Java Province ranks the highest in Indonesia with 99,398 cases and the province with the lowest cases is West Papua with 551 cases [3].

Evaluation is a tool or procedure that is used to find out and measure something in an atmosphere in a predetermined manner and rules. From the evaluation results are usually obtained about the attributes or properties contained in the individual or object in question. In addition to using tests, data can also be collected using questionnaires, observations, and interviews or other appropriate forms of instruments. Assessment activities in program evaluation are not only carried out at the end of program activities, but should be carried out from the beginning, namely, from the preparation of program design, program implementation, and the results of the program [4]. 
West Palu Sub-district is an area with the most TB cases based on reports from health centers and hospitals. Kamonji Puskesmas is one of the endemic areas for TB cases, there were 106 TB cases that were treated in 2019, at Tipo Puskesmas there were 42 TB cases, at Sangurara Puskesmas there were 46 TB cases, and in Nosara Puskesmas there were 17 cases. Puskesmas Nosara is a health center that has the lowest number of TB case findings among the 13 health centers in Palu City, this is because the Nosara Puskesmas is a new Puskesmas and the facilities and infrastructure in that Puskesmas are incomplete [5].

Based on the description above, the authors are interested in researching the Evaluation of TB Control (TBC) in TB Case Finding in the Work Area of the Nosara Community Health Center, Palu City.

\section{Materials and Methods}

The research method used is qualitative. Research is carried out with a case study approach, namely in-depth research on individuals, groups, organizations, program activities, and so on within a certain period of time. The goal is to get a complete and in-depth description of the content [6].

This research was conducted at the Puskesmas Nosara, Palu City in April-May 2020.

This study uses the determination of informants by purposive sampling with a total of six informants. The informants in this study were the head of the Puskesmas, the holder of the TB program, the implementer of the TBC program, the TB paisen who was doing the treatment at the Nosara Puskesmas and the families of the TB patients. Data collection in this study was carried out through in-depth interviews, observation, documentation. The instruments used were interview guides, observation sheets, and documentation.

\section{Results}

\section{Input \\ Man (human resources)}

The health workers at the Nosara Puskesmas are adequate, in terms of quantity, the number of health workers available in the TBC program consists of one program holder who is in charge and is responsible and coordinates all activities from planning, implementation and evaluation in the TB program. At the Nosara Puskesmas, Palu city with a D3 Nursing educational qualification, 1 TB Program implementing officer with a S1 public health qualification and three general practitioners. Meanwhile, with regard to cadres, Puskesmas Nosara has yet to have a special cadre of TB that focuses on assisting the implementation of TB case detection programs in the community.

In terms of quality, the TBC program officers at the Nosara Puskesmas are inadequate because TB program holders have never attended any training even though training is needed by program holders to improve its quality.

\section{Money (fund)}

The budget for the TBC program comes from the Health Operational Assistance (BOK) fund which is used to meet needs such as off-field activities in the form of transportation costs or other out-of-field activities. The results of interviews with informants stated that the available budget was sufficient to carry out program activities. The flow of funding for the Nosara Puskesmas comes from the Palu City Health Office in the form of BOK funds that are submitted every 8 months and are allocated for case tracking, Prime Minister's Office (PMO), and guidance against infectious diseases. At the end of each year the Puskesmas submits a Power of Attorne that has been compiled to the Palu City Health Office, and then the Palu City Health Office verifies the proposed activity. Activities that have been verified will be carried out by the Puskesmas in the following year.

\section{Materials (facilities and infrastructure)}

The facilities and infrastructure for the discovery of TB cases at the Nosara community health center are inadequate because there are no laboratory equipment that can support the examination of the patient's sputum and the special TB program room which is too close to other program rooms but the availability of drugs and administration is adequate.

\section{Method}

The method used by the TB program at Puskesmas Nosara in case finding prioritized active case finding rather than passive case finding. The active TB case discovery referred to by the Puskesmas is by going directly to the community when the Puskesmas is given information about the community who shows symptoms of TB disease, the examination is immediately carried out, the laboratory results that show positive will be carried out by house contact checks so that it can be known if there are other family members infected so that treatment can be done immediately. Meanwhile, passive case finding is meant by waiting for a patient to come to the Puskesmas for examination. 


\section{Process}

\section{Planning}

Planning in the TBC Program at the Nosara Community Health Center has been well realized, planning is carried out by compiling a proposed activity plan (RUK) and at the end of each year each program evaluates a report on the activities they are working on after that each program proposes a follow-up plan (RTL) to the health office.

\section{Organizing}

The responsibilities given are in accordance with the duties assigned to each officer and those involved in the implementation of the TBC program in the detection of TB cases, namely, the person in charge of the TB program and the existence of cross-program cooperation and cross-sector cooperation also held with sub-districts, sub-districts and involvement local community in TB case finding activities by providing information to health workers if there is a community showing clinical symptoms of TB disease. Evaluation has also been carried out by the Puskesmas through a workshop which is routinely carried out every month, where program holders report their activities in implementing the TBC program

\section{Actuating}

The implementation of the TBC Program has been running according to the RUK but has not been carried out optimally, there are obstacles faced by officers when taking sputum samples where there are still some people who find it difficult to expel sputum when the officers are tracking cases. Officers are very concerned about the treatment carried out by TB patients by always monitoring and reminding patients to pay attention to their treatment so that no patient experiences dropouts. In its implementation, the TB program also collaborates with other programs so that when the officer gets information that a suspect has been found in an area, the officer immediately takes action by conducting an examination and taking a sputum sample, if a positive result is obtained, the officer immediately contacts the patient to do so treatment. Officers also make home visits to take sputum samples from the patient's family.

\section{Controlling}

Supervision is carried out by the head of the Puskesmas by monitoring all activities in each program in the Puskesmas, including the TBC program and monitoring it every month through Lokmin activities. The head of the Nosara Puskesmas always receives reports of activities carried out by each program, checks to see if any obstacles are encountered so that they can find the best solution that can be done so that program activities can be carried out properly. The special supervisor in the process of implementing the TBC program is the health office, every month the TB program report is submitted to the health office.

\section{Output}

The output of the TBC program in the discovery of TB cases in the work area of the Nosara community health center in Palu city has not been maximized, the Nosara Puskesmas has not met the targets of the TB Program that has been set. The obstacles that were found were the lack of cases in the working area of the Nosara Puskesmas and the presence of patients who did not complete treatment; most cases of incomplete treatment of these patients were caused by people who came from outside the area.

\section{Discussion}

\section{Input}

Man (human resources)

Human resources are an aspect that is very important for the achievement of success in governance, implementation of development, and improving services to the community [7].

TBC Program in TB Case Discovery in the work area of the Nosara community health center in Palu city, in quantity there is still a shortage of health personnel to carry out the TBC Program in TB case discovery, especially for TB program holders who are assigned and responsible for carrying out TB program activities, coordinating all activities starting from planning, implementation, and evaluation in the TB (TBC) Control program at the Nosara Community Health Center, Palu City. In addition, program holders also have a double workload, such as being responsible for the malaria and leprosy program; with the double workload carried out by the TBC program manager causing program managers not to do their job optimally this can affect program achievement.

The Nosara Puskesmas also does not yet have a special cadre to assist the TBC program in carrying out case finding activities even though the role of cadres is very important in assisting case finding and conducting general education in the community because by providing counseling to a group of people or in general, it is hoped that the community will know more about its importance. Maintain health and know about the clinical symptoms of TB disease so that the community can help the TB program at the Nosara Puskesmas in case finding. 
Human resources or health workers at the Puskesmas have a role as implementing health workers. In this role, it is expected that the main tasks and functions (tupoksi) of health workers are in accordance with the education and skills they have. TB program holders at the Nosara Puskesmas have a double workload, this is because in planning for the placement of personnel, the Puskesmas management still has not carried out a job analysis that can see the workload of each person in charge of the program and this is also because the number of health workers at the Puskesmas is not proportional with the type of program being worked on.

In terms of quality, the officer in charge of TB has never attended any training. TB program holders only rely on the basic knowledge previously obtained or find out for themselves the latest information related to TB disease. Whereas training is an important thing that must be followed by health workers to have good knowledge and skills to carry out their duties so that they can become productive health workers who are able to do their job well and in accordance with existing provisions, as stated in the Minister of Health Regulation. No. 67 of 2016 concerning TBC that training is one of the efforts to increase the human resources of TB by increasing the knowledge, attitudes, and skills of officers to improve the competence and performance of officers [8].

\section{Money (fund)}

Funds are the most important thing for an activity to run, without funds an activity will not be able to run. The input standard stipulates the minimum requirements for the input elements needed to be able to provide quality health services, namely, the type of number and qualifications of implementing personnel, types, amounts and specifications of suggestions, and the amount of funds [9].

Budget resources in the TBC in TB case finding in the work area of the Nosara health center, Palu city are not problematic if only to carry out activities that have been specified in the Activity Proposed Plan. The budget received by the program is sufficient to carry out activities because it is bottom up, depending on the program manager and the proposed activity plan prepared by the program manager. However, there is no special funding provided by the government in the provision of facilities and infrastructure such as laboratories and supporting equipment in examining the sputum of TB patients at the Nosara Community Health Center so that in carrying out laboratory examinations, there are obstacles that cause the health center to refer sputum samples to the Sangurara Health Center.

\section{Materials (facilities and infrastructure)}

According to Chotimah (2018), in the pulmonary TB program, facilities are anything that is used as a tool to achieve certain goals, while infrastructure is anything that is used as a support in carrying out an activity, because in the pulmonary TB program it cannot be separated from the availability of facilities and infrastructure to support the success of the program [10].

The facilities and infrastructure that support the implementation of the TBC Program in the Discovery of TB cases in the work area of the Puskesmas Nosara, Palu City are still inadequate, but most of them are sufficient, including medicines, recording and reporting books, sputum pots. But there are some facilities that are still inadequate and inadequate, such as the absence of a special room for TB patients to provide services at the Puskesmas, the location of the TB program room is also very close to other program rooms, this can be dangerous for TB disease transmission. With the existence of a special room for the TB program, it is hoped that patient privacy will be more maintained, as stated Zarwita (2019), that another factor that could be the cause of the low discovery of pulmonary TB sufferers is the shame of pulmonary TB sufferers to check themselves into health facilities [11].

The Nosara Puskesmas also does not have a laboratory room and equipment that meets the standards for examination, so the Puskesmas needs to refer sputum samples from TB patients to Sangurara Health Center. This can cause patients to take longer to wait for the test results. Whereas incomplete facilities and infrastructure can hinder officers from finding new cases and affect the achievement of TB targets.

The facilities and infrastructure for the achievement of pulmonary TB CDR are one of the things needed to support a pulmonary TB prevention program. Based on the national TBC guidelines from the ministry of health of the republic of Indonesia in 2008, laboratory facilities and infrastructure used in the achievement of pulmonary TB CDR include: (a) Laboratory equipment, consisting of microscopes, slide boxes, sputum pots, glass preparations, dye racks and dryers, alcohol lamps, ose, plastic bottles with pipettes, microscope lens cleaning paper, and filter paper. (b) Diagnostic materials consist of Ziehl Neelsen reagent, alcohol ether, immersion oil, lysol, and tuberculin purified protein derivative RT 23. (c) Printed materials such as manuals, recording forms and reporting (TBC 01 to TBC 07) [1]

\section{Method}

The method of implementing the TBC program in TB case finding in the work area of the Puskesmas Nosara, Palu city is in accordance with the guidelines, namely, passive case finding and active case finding, but in its implementation at Nosara Puskesmas it prioritizes active case finding rather than passive case finding. The active TB case discovery referred to by the Puskesmas is by going directly to the community when 
the Puskesmas is given information about the community showing symptoms of TB disease, the examination is immediately carried out, the laboratory results that show positive will be carried out by house contact checks so that it can be known if there are other family members infected so that treatment can be done immediately. Meanwhile, passive case finding is meant by waiting for the patient to come to the Puskesmas to have himself examined. In fact, finding new cases outside the field should only be done if it is really needed in areas where TB patient contacts are suspected. Officers should emphasize more passive discovery at the health center by providing counseling and motivating patients actively in the Puskesmas as well as collaborating across sectors and programs to provide counseling and finding new cases in the community.

Case finding activities can also be carried out with the help of special TB cadres because cadres have a very important role in case finding activities. Cadres have a role as counseling providers related to TB disease, helping find people suspected of having TB disease, assisting Puskesmas in guiding and motivating PMOs to always supervise drug swallowing, become $\mathrm{PMO}$ coordinators, and if patients do not have PMOs, cadres can become PMOs. According to research conducted by Yani (2018), it is stated that the participation of TB cadres can effectively and optimally increase the rate of cure for TB by up to $80 \%$. Empowerment of TBC cadres is proven to provide changes in increasing the cure rate for TB disease. TB patients in Kenya who take advantage of the presence of TB cadres can increase the cure rate by $83 \%$ compared to TB patients who do not take advantage of the presence of these cadres only reached $68 \%$ [12].

\section{Process}

\section{Planning}

Of the various administrative functions that are known, the most important of which is the planning function. Planning is a work that involves drafting concepts and arranging activities to be carried out to achieve the goals that have been set for a better future [9].

TB program planning has been well realized. The planning process is carried out to formulate work steps to achieve program objectives. Planning is carried out by compiling a proposal for activities (RUK) and submitting the RUK in the community health center Lokmin activities to obtain input. At the Lokmin, monitoring was also carried out to assess how far the program had achieved and what obstacles were encountered and then formulated an activity implementation plan (RPK). After the evaluation is carried out, the program proposes a follow-up plan (RTL) for the problems it finds to the Health Office.
Planning is an important stage to carry out program activities, without careful planning a program cannot run effectively. Planning carried out in the TBC program starts from describing the problem to get a comprehensive picture of the problems faced from the various factors that influence it, then determining targets after that outlines all operational health programs and can be supervised or controlled.

\section{Organizing}

Organizing is a series of activities in the management function that includes the collection of all resources or potential belonging to the organization for efficient use in achieving goals [7].

The TBC program already has a job description to be responsible for activities and is understood by each officer. However, the job descriptions have not been able to be carried out optimally due to the multiple duties assigned to the TB program holder as the person in charge of malaria and leprosy.

The TB program at the Nosara Puskesmas also collaborates across programs and across sectors such as sub-districts, sub-districts and local community involvement in TB case finding activities by providing information to health workers if there is a community showing clinical symptoms of TB disease. Every month the Puskesmas conducts Lokmin activities to see that the responsibility given is appropriate or not.

The organization carried out in the TBC Program at the Nosara Community Health Center was not suitable, with the division of tasks for TB program holders which would result in a more workload resulting in the inadequate implementation of the TBC Program in Case Finding at the Nosara Health Center which could affect the achievement of the TB program.

\section{Actuating}

After planning and organizing have been completed, then what needs to be taken in administrative work is to make the plan using the organization that is formed into a reality. This means that the plan is implemented and/or actualized [9].

The implementation of the TBC Program in the Discovery of TB cases in the work area of the Puskesmas Nosara, Palu city is in accordance with the RUK, the obstacles that are obtained come from the community, namely, people who do not want to collaborate to carry out examinations, there are patients who cannot expel phlegm and many are still found patients who do not understand how to expel phlegm. However, in implementation, program officers always pay attention to the treatment performed by TB patients. Officers always monitor patients who seek treatment to carry out their treatment completely and prevent patients who drop out of treatment. 
Disobedience of the patient's family to household contact examinations can cause new cases in the community because the highest risk for TB infection is someone who has the longest contact with TB patients, especially if their immune system is not good. The risk also increases if the person who has a cough does not cover his mouth with a handkerchief. TB bacteria can survive in the air for a very long time until they are inhaled through human respiration and can only die by exposure to direct sunlight. In addition, smear positive with faster transmission is more common in adults, so it is suggested that household contact checks will be very important to reduce TB disease transmission and increase the case finding coverage rate for TB disease in the community.

\section{Controlling}

Supervision is a process for measuring the appearance of an activity or the implementation of a program which then provides directions so that the stated objectives can be achieved [13]

Controlling is a monitoring process carried out routinely by the leadership of the Puskesmas or the health office on the implementation of TB case detection at the Nosara Puskesmas. Supervision is carried out to control whether the TB program activities have been running effectively and efficiently or not and so that the TB program activities do not deviate from the objectives to be achieved.

The supervision carried out on the TBC program at the Nosara Puskesmas has been running well, the supervision is carried out by the Head of the Puskesmas through Lokmin activities, supervision is carried out by controlling program activities that have been running well or experiencing obstacles. Each program also reports the results of its activities. At the end of each year, the Puskesmas also reports all results of its activities to the health office.

\section{Output}

Output is a collection of parts or elements resulting from the process in the system. Output is an administrative job for health administration; this output is known as health services [9].

The achievement of TB case detection at the Nosara community health center in Palu city in 2019 was $22 \%$, while the case finding target of the central Sulawesi Provincial health office in 2019 was $80 \%$, which means that the Nosara Puskesmas has not reached the predetermined target of TB case finding This could prove that the implementation of TB case finding at the Nosara community health center was not optimal. Not optimal detection of TB cases at Puskesmas Nosara is certainly influenced by aspects of input that is not fulfilled maximally, among others: In terms of quantity, the lack of human resources at Puskesmas Nosara causes TB program holders to have a double workload, in terms of quality the TB program holders have never attended any training, as well as inadequate facilities and infrastructure such as laboratory rooms that do not meet standards. By not maximizing the input aspect, it will affect the running of the process aspect; this will greatly affect the achievement of the TBC program in the detection of TB cases at the Nosara Health Center (output).

Efforts that have been made by the TBC program officers at the Nosara community health center to prevent the transmission of TB disease are conducting a home visit by monitoring the patient's taking medication to prevent patients who drop out of treatment.

\section{Conclusion}

The input of the TBC program in TB case finding at the Nosara community health center is inadequate from a human perspective because TB program holders have a double workload and have never attended training. In terms of money/funds are sufficient. In terms of material, it is not sufficient because it does not have a laboratory that meets the standards for examining sputum in TB patients. In terms of method, it is in accordance with the guidelines, namely, passive case finding and active case finding, but in its implementation, active case finding is more important.

The TBC program in TB case finding at the Nosara community health center in terms of planning has been well realized by compiling a RUK. In terms of organizing, there is a division of duties but due to a lack of human resources, there is still a double workload. The TBC program has collaborated across programs and sectors. In terms of actuating, it is in accordance with the RUK but there are still some obstacles when carrying out case tracking activities. In terms of controlling, it was carried out by the person in charge of the TBC program, the Head of the Nosara community health center and the health office.

The output of the TBC program in TB case discovery at the Nosara health center has not reached the target of $22 \%$ while the target of case finding achievement from the Central Sulawesi Provincial health office in 2019 is $80 \%$.

\section{References}

1. Nugraini KE, Cahyati WH, Farida E. Evaluation of pulmonary tb case detection rate (cdr) achievement input in puskesmas 
pulmonary tb disease control (p2tb) 2012 (qualitative study in semarang city). Unnes J Public Health. 2015;4(2):143A-52.

2. World Health Organization. Global Tuberculosis Report 2019. Geneva: World Health Organization; 2019.

3. Kemenkes RI. Indonesian Health Profile Data and Information. Jakarta: Kemenkes RI; 2010.

4. Muryadi AD. Program evaluation model in evaluation research. Sci J Phys Educ 2017;3:1A-16.

5. Palu City Health Office. Palu City Health Profile 2018. Palu: Palu City Health Office; 2018.

6. Swarjana IK. Health Research Methodology. Yogyakarta: CV Andi Offset; 2015.

7. Darmawan AS, Sjaaf AC. Public Health Administration Theory and Practice. Jakarta: Rajawali Pers; 2016.

8. Permenkes RI. Regulation of the Minister of Health of the Republic of Indonesia Number 67 of 2016 Concerning
Tuberculosis Control. Jakarta: Permenkes RI; 2016.

9. Azwar. Introduction to Health Administration. Jakarta: Binarupa Aksara; 2010.

10. Chotimah I, Oktaviani S, Madjid A. Evaluation of lung tb program in puskesmas belong center Bogor in 2018. Promot Public Health Stud J. 2018;1(2):87-95.

11. Zarwita $D$, Rasyid R, Abdiana. Analysis of the implementation of lung tb patient discovery in the lung tuberculosis control program at balai puskesmas Tuesday. Andalas Health J. 2019;8(3):689A-99.

12. Yani DI, Hidayat RA, Windani C, Sari M. Description of the implementation of the role of the tuberculosis Kader in the dots program in Bandung Kulon sub-district. J Comprehensive Nursing. 2018;4(2):58-67.

13. Notoatmodjo. Public Health Sciences. Jakarta: PT Rineka Cipta; 2014. 